\title{
Preparation and Properties of Pesticide/Cyclodextrin Complex Intercalated into ZnAl-Layered Double Hydroxide
}

Xiaoguang Zhang, ${ }^{* \dagger}$ Jiexiang Liu, ${ }^{\ddagger}$ Wanguo Hou, ${ }^{\S}$ Jun Tong, ${ }^{\dagger}$ Luying Ren,${ }^{\dagger}$ Guoying Sun, ${ }^{\dagger}$ $\mathrm{Ya} \mathrm{Sun}^{\dagger}$

${ }^{\dagger}$ College of Chemistry, Nankai University, Tianjin 300071, People’s Republic of China,

${ }^{\ddagger}$ School of Chemical Engineering, Hebei University of Technology, Tianjin 300130, People’s

Republic of China, and

${ }^{\S}$ Key Laboratory for Colloid \& Interface Chemistry of Education Ministry, Shandong University, Jinan 250100, People's Republic of China

\section{Supporting information}

FT-IR spectra of HECD and SHECD (Figure S1). The ${ }^{1} \mathrm{H}$ NMR spectrum of HECD (Figure S2). The structures of bifenthrin and cyhalothrin (Figure S3). TGA (A) and DTA (B) curves of LDH and BC (Figure S4). This material is available free of charge via the Internet at http://pubs.acs.org.

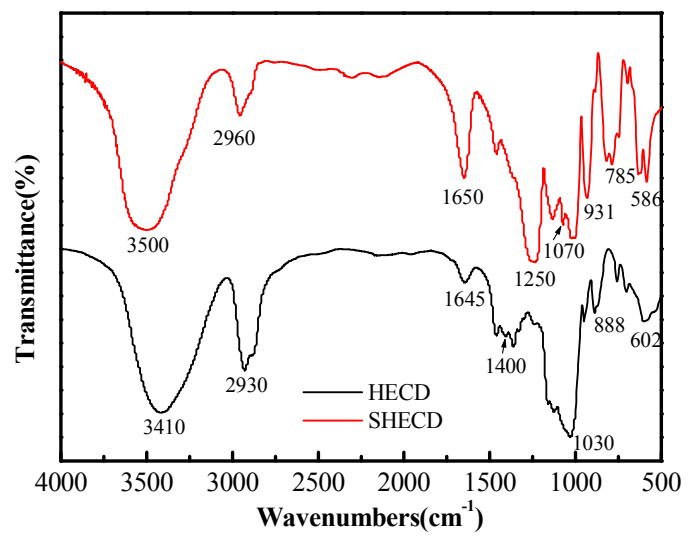

Figure S1 FT-IR spectra of HECD and SHECD 


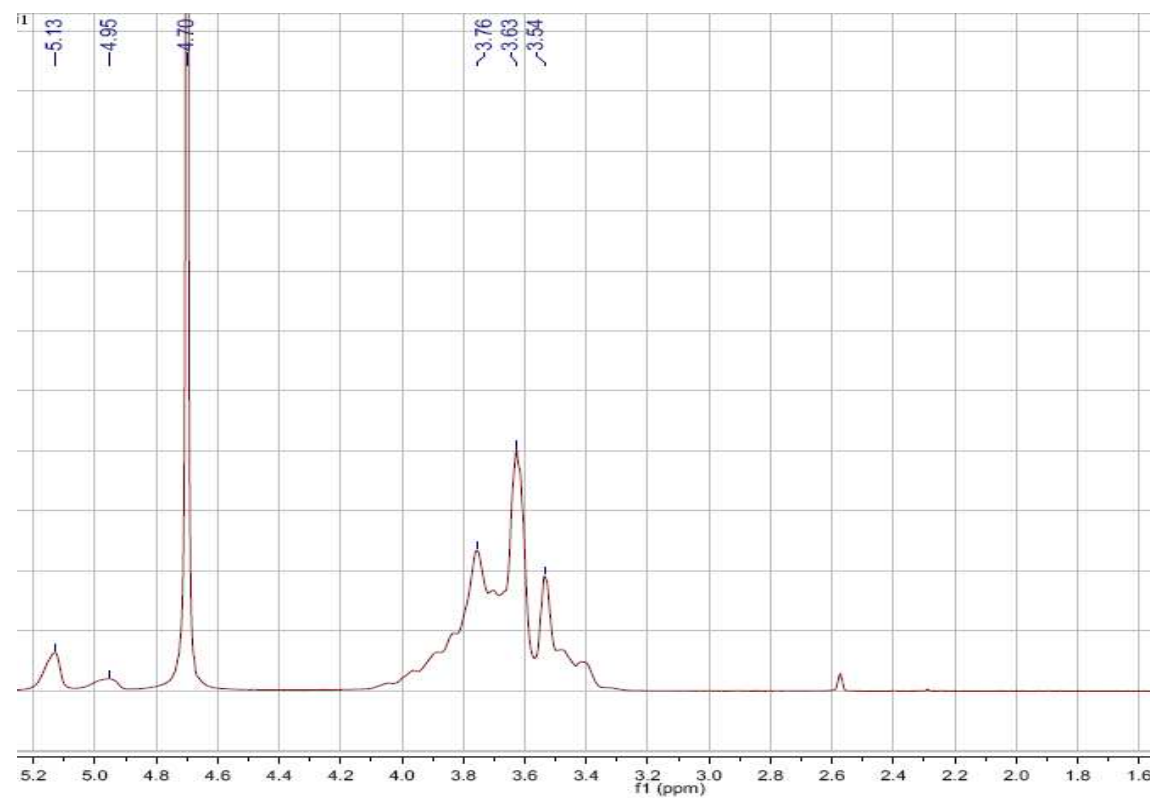

Figure S2 The ${ }^{1} \mathrm{H}$ NMR spectrum of HECD

FT-IR spectra of HECD and SHECD, and the ${ }^{1} \mathrm{H}$ NMR spectrum of HECD are presented in Figure S1 and S2, respectively. In FigureS1, compared to HECD, there are two adsorption peaks (1250 and $1070 \mathrm{~cm}^{-1}$ ) appeared in SHECD, which are attributed to the stretching vibration of $\mathrm{SO}_{2}$ and $\mathrm{S}-\mathrm{O}-\mathrm{C}$, respectively, indicating existence of $-\mathrm{SO}_{3}$. DS of $\mathrm{HECD}$ can be calculated according to the peak area ratio between chemical shifts (3.3-4.1) and (4.9-5.2), and the structure of $\beta-\mathrm{CD}$. The peak area ratio between chemical shifts (3.3-4.1) and (4.9-5.2) is 12.59 , and DS of HECD is $(12.59 \times 7-42) / 4=11.5$, its molecular weight is 1641 . The sulfur (S) percentage of SHECD compound has been measured by ion chromatography, which is $9.49 \%$. The mole number of $\mathrm{S}$ in SHECD is the same as that of $\mathrm{SO}_{3}$ group, hence $w(\mathrm{~S})$ can be calculated by the equation:

$$
w(\mathrm{~S})=\mathrm{xM}(\mathrm{S}) /\left[\mathrm{xM}\left(\mathrm{SO}_{3}\right)+\mathrm{M}(\mathrm{HECD})-\mathrm{x}\right] \times 100 \%
$$

Here $\mathrm{x}, \mathrm{M}(\mathrm{S}), \mathrm{M}\left(\mathrm{SO}_{3}\right), \mathrm{M}(\mathrm{HECD})$ are $\mathrm{DS}$, the atomic weight of $\mathrm{S}$ element, the molecular weight of $\mathrm{SO}_{3}$ group, and the molecular weight of HECD, respectively.

$$
[32 \mathrm{x} /(80 \mathrm{x}+1641-\mathrm{x})] \times 100 \%=9.49 \%, \mathrm{x}=6.4
$$

DS of SHECD is 6.4 . 


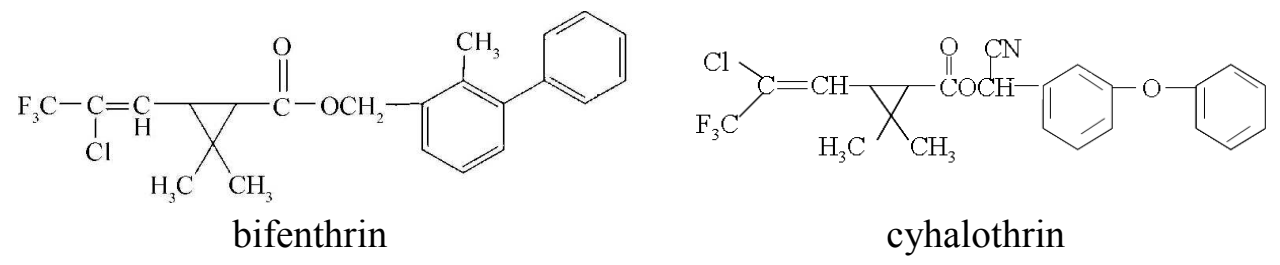

Figure S3 The structures of bifenthrin and cyhalothrin
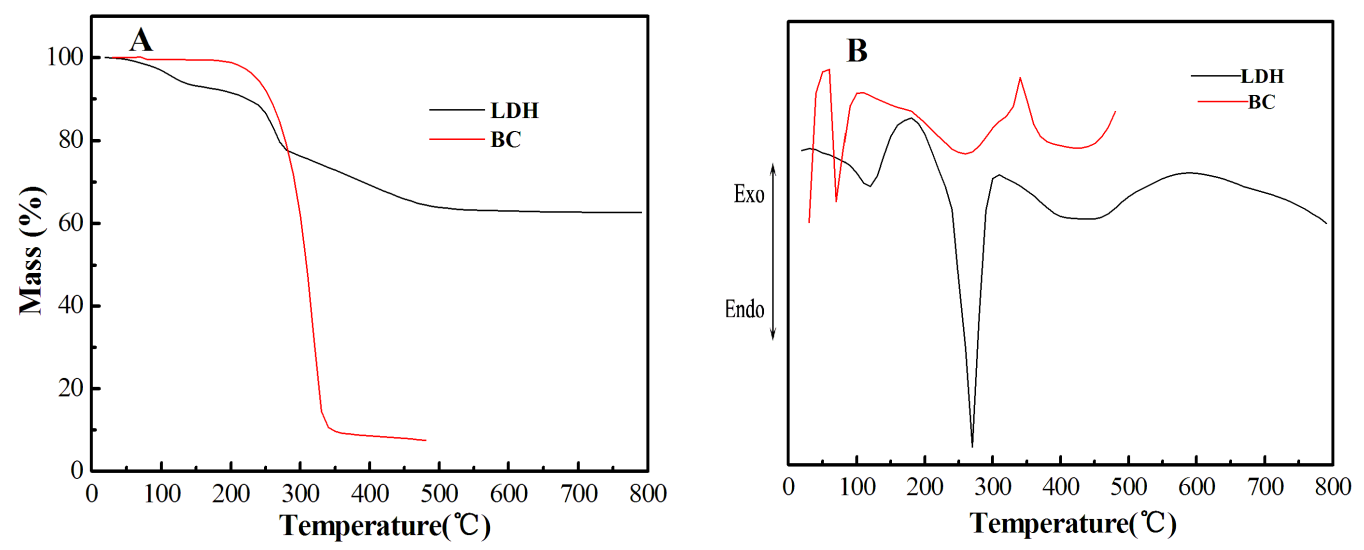

Figure S4 TGA (A) and DTA(B) curves of LDH and BC 